\title{
Fronteiras e identidades: os Manchineri e os Jaminawa na tríplice fronteira Brasil- Bolívia-Peru
}

\author{
Rinaldo Sérgio Vieira Arruda \\ Doutor em Ciências Sociais (Pontifícia Universidade Católica de São Paulo) \\ Professor da Pontifícia Universidade Católica de São Paulo \\ São Paulo, SP, Brasil \\ rinaldo@pucsp.br
}

\begin{abstract}
Resumo Este artigo versa sobre as vicissitudes dos povos hoje conhecidos como Manchineri e Jaminawa, habitantes das regiões fronteiriças do departamento de Pando, na Bolívia, de Madre de Dios, no Peru, e do estado do Acre, no Brasil. Procura traçar suas conexões e pertinências histórico-identitárias como povos de filiação linguístico-cultural Arawak e Pano, apontar o processo de seu envolvimento pela expansão das sociedades nacionais da Bolívia, do Peru e do Brasil, impulsionadas pela exploração da borracha na região, e, finalmente, mostrar como sua atual definição político-identitária e suas condições de vida foram conformadas por esses processos. Mas, ainda que conformados por esse envolvimento e pelas normatizações dos Estados nacionais que repartiram seu território em fronteiras nacionais, impondo os marcos "legítimos" para a vida de seus habitantes, apontamos como intentam instrumentalizar esses parâmetros legais e socioculturais que procuram submetê-los.
\end{abstract}

Palavras-chave: Manchineri, Jaminawa, fronteiras, identidades, Estado-nação, etnicidade.

\section{Introdução}

\begin{abstract}
A formaÇão da fronteira trinacional Brasil, Bolívia e Peru ocorre como uma dinâmica social complexa, entrelaçada a processos de escala regional, nacional e mundial. Mas, ainda que determinada por esse macroprocesso de longa duração (a formação do capitalismo, a ocidentalização do mundo e a formação de um sistema mundial), foram os processos e atores sociais locais que moldaram as formas de ocupação do espaço, de definição de fronteiras e de lógicas políticas e identitárias. Não vamos nos estender sobre esses macroprocessos, mas apenas apontar suas manifestações mais evidentes na região estudada, cuja configuração, como veremos mais adiante, foi marcada pela industrialização europeia e norte-americana, no seio das quais se desenvolveram novas tecnologias de aproveitamento da borracha (vulcanização) e novos tipos de veículos, tais como automóveis e bicicletas, além de um sem-número de mercadorias que passam a utilizar a borracha como um de seus componentes. A abertura desse enorme e crescente mercado impulsionou os países fronteiriços aqui referenciados a promover, por diversos processos, a ocupação de seus territórios amazônicos, cujas matas abrigavam a fonte da borracha, desencadeando os processos regionais nos quais as populações desses países confrontantes se viram envolvidos, assim como os povos indígenas que ali viviam.
\end{abstract}


Esses atores locais, impulsionados pela lógica econômica dos macroprocessos referidos, ocuparam esse espaço palmo a palmo, disputando-o com as populações indígenas locais e incorporando-as aos processos extrativos da borracha.

Esta reflexão é parte de pesquisa mais ampla sobre essa tríplice fronteira, envolvendo pesquisadores da Pontifícia Universidade Católica de São Paulo (PUC-SP), da Universidade Federal do Acre (UFAC), da Universidade de São Paulo (USP) e da Universidade Federal do Ceará (UFC), no Brasil; da Universidad Pablo de Olavide (UPO), de Sevilha, na Espanha, e da Universidad San Antonio Obispo (USAO), de Cuzco, no Peru. A pesquisa foi realizada em 2008 nas cidades fronteiriças de Assis Brasil, no Brasil, de Bolpebra, na Bolívia, e de Iñapari, no Peru, localizadas nas margens do rio Acre, perto de sua confluência com o rio Iaverija, cursos d'água que demarcam as fronteiras entre esses países.

No caso dessa região de estudo, tem-se o aproveitamento de uma matéria-prima descoberta e utilizada pelos povos indígenas americanos (a borracha), mencionada já por Colombo nos primeiros contatos com os nativos, e a formação de um sistema econômico mundializado como elementos fundamentais para os processos de ocupação da região. Originalmente, a borracha era usada para a confecção de bolas, para a impermeabilização de artigos de vestuário, na fabricação de tochas e para várias outras finalidades. Esse produto, que para os ocidentais foi de início uma mera curiosidade sem finalidade comercial aparente, passou a ser exportado para os Estados Unidos e a Inglaterra ainda no século XVIII, na forma de sapatos e botas revestidos de borracha, fabricados em Belém do Pará. Mas foi o aprofundamento e a expansão da Revolução Industrial e a formação do capitalismo monopolista, aliados a novos processos de tratamento da borracha, que abriram um mercado internacional para a borracha e desencadearam o processo de ocupação e definição fronteiriça da região a que nos referimos.

Em meados do século XIX, a Revolução Industrial iniciada na Inglaterra se estendeu por toda a Europa, pelos Estados Unidos, pelo Canadá e pela Austrália, multiplicando a demanda por novos produtos como o aço, o petróleo, a eletricidade e a borracha, a qual passou a ser consumida em grande escala, principalmente pela Inglaterra e pelos Estados Unidos. Manaus, no Brasil, tornou-se o centro desse movimento caucheiro e seringueiro, porto principal para a exportação da borracha.

Área mais distante e "vazia" dos três países, últimas fronteiras a serem definidas, a região do Acre e do sul do Amazonas torna-se importante como fonte de extração de borracha, principalmente após a descoberta do processo de vulcanização por Charles
Goodyear em 1839, fazendo com que a goma elástica se tornasse resistente à mudança de temperatura. A província do Amazonas já registrava um volume de 236.150 arrobas de borracha exportadas de 1853 a 1867 . Na mesma época, o caucho começa a chegar no Pará, trazido de pontos remotos da região dos formadores do Javari, do Juruá e do Purus (Cunha, 2000).

A penetração e a fixação territorial, moldadas pelos processos de extração da borracha para alimentar o mercado mundial, tomam as características das frentes de expansão dos três países que disputam o domínio sobre as fontes da goma elástica. Os dois modos de extração da borracha - o caucho extraído de uma só vez, com a derrubada da árvore que o produz (castilloa elástica), e a seringa, extraída de forma regular ao longo do tempo, mantendo-se o aproveitamento das mesmas árvores por longo período (hevea brasiliensis) - induziram formas diferenciadas de povoamento. O caucho, presente principalmente nos vales do Madre de Dios e do Ucayali e espraiando-se pelo rios do Baixo Purus quase até além do Ituxi (Cunha, 2000, p. 278), induziu um povoamento nômade, de terra arrasada, da penetração contínua sem fixação. A seringa, presente na bacia do rio Acre e em quase toda a Amazônia, mas em menor densidade na área ocupada pelo caucho, provocou uma ocupação mais permanente, a formação de núcleos e a fixação na mata.

Esse movimento é impulsionado pelos países fronteiriços através da formação de expedições de reconhecimento, da concessão de terras e da presença militar em vários momentos, a fim de garantir a ocupação já realizada ou de contrapor-se à penetração dos países vizinhos (Alves de Souza, 2005; Camacho, 2003; Cunha, 2000; Lossio, 2002 e outros). A província do Amazonas, oficialmente criada em 1852 no território da comarca do Rio Negro, organizou expedições exploratórias pelas bacias dos rios Juruá e Purus. Além da exploração da região e de suas riquezas naturais, as primeiras expedições oficiais, lideradas respectivamente por João Rodrigues Cametá e Romão José de Oliveira, tinham como objetivo a atração e a pacificação dos índios (Coutinho, 1862; Chandless, 1949; Alves de Souza, 2005). Essas entradas permaneceram limitadas, subindo os rios apenas parcialmente, mas inauguraram uma série de explorações durante as décadas de 50 e 60 do século XIX, mapeando a região e orientando suas consequentes penetração e ocupação pelos seringalistas e caucheiros. Esse processo não respeitou fronteiras e tratados estabelecidos no papel, desencadeando vários conflitos e disputas para a redefinição desses limites. Assim, as linhas fronteiriças foram fruto do movimento dessas frentes de expansão e de seus enfrentamentos na luta pela posse das rotas de extração da goma, luta essa que incorporou os povos 
indígenas regionais, às vezes como escravos, outras como aliados momentâneos em paralelos conflitos faccionais (Castelo Branco, 1958 e 1961; Delboy, 1912; Cunha, 2000).

Este é um exemplo típico de uma fronteira em movimento caracterizada por constantes mudanças e transformações em relação aos seus componentes populacionais (povos indígenas, portugueses, espanhóis, depois brasileiros, bolivianos e peruanos, depois migração cearense etc.) e pelas mudanças na demarcação política. Só no início do século XX se formalizam os atuais limites entre Bolívia e Peru (1902), Bolívia e Brasil (1903) e Peru e Brasil (1909).

\section{A antiguidade dos povos indígenas da tríplice fronteira}

As populações originais da região da tríplice fronteira, das quais os atuais habitantes Manchineri e Jaminawa são uma continuidade, eram formadas por diversos povos, mencionados por vários autores ao longo da ocupação da região (Carvajal, [1542]1941; Acuña [1639]1941; Haenke [1796]1974; Coutinho, 1862; Von Hassel, 1905; Delboy, 1912; Castelo Branco, 1947, 1950 e 1958; Cunha, 2000; Tocantins, 1979). Esses povos eram, em sua maioria, de filiação linguístico-cultural Arawak e Pano. Os Arawak ocupavam principalmente a bacia do rio Purus, e os de filiação Pano distribuíam-se majoritariamente pela bacia do rio Juruá. Entretanto, essa distribuição não era tão uniforme assim e insere-se numa dinâmica histórica milenar de deslocamentos, aproximações e afastamentos, agudizando-se na época do boom da borracha e que se processa ainda hoje.

Por milênios houve uma fronteira entre as terras altas e a Amazônia, separando os povos andinos dos Arawak e dos Pano das margens do Ucayali. Os de filiação Pano vinham até essa fronteira para comerciar e muitas vezes defendê-la, em conjunto com os Arawak, configurando uma área Arawak que tangenciava a fronteira ecológica andina e uma área Pano nas terras baixas. De acordo com Lathrap (1970, p. 74), por volta de 3000 a.C., os proto-Arawak concentravam-se na várzea do médio Amazonas, perto da atual Manaus. Seu crescimento demográfico teria esgotado as possibilidades das terras aluviais da planície amazônica, provocando ondas migratórias, desde cerca de 5 mil anos atrás, para o médio e alto Ucayali, onde sua presença é comprovada há 4,5 mil anos, embora possa ser mais antiga. Os antigos Pano, por sua vez, migraram em direção ao Ucayali por volta de 100300 d.C., aparentemente vindos da região do Beni e do Guaporé, no norte da Amazônia boliviana (Erik- son,1998, p. 244-248). Os Pano teriam avançado pelo interior e fixado-se no Ucayali e em seus afluentes, onde teriam reinado absolutos até cerca de 700-800 d.C. Nessa altura, processa-se nova intrusão dos Arawak, seccionando o conjunto Pano, um pouco abaixo do Pachitea.

Estudos arqueológicos indicam nessa época uma ocupação densa em Cumancayacocha, no médio Ucayali. Além da cerâmica sofisticada, encontraram-se ali também machados de cobre, considerado traço incontestável de uma conexão andina. Lathrap (1985), apoiando-se em dados arqueológicos e nas mitologias pano (como a dos Kashinawa, Cashibo e Conibo), que mencionam repetidas vezes heróis culturais chamados Inka, e mitos Shipibo que evocam "a época em que vivíamos em Cumancaya sob o domínio Inka", propõe que ali havia uma chefia pluriétnica hierarquizada, com predominância de falantes de língua quechua, os quais dominavam os Pano. Apesar de polêmica, essa teoria parece ser referendada pela maior parte dos povos indígenas do Ucayali: "todas se vangloriam de ter sido dominadas pelos Incas. Os Conibo afirmam que são os antigos habitantes dos arredores de Cuzco, os Shipibos, segundo dizem, teriam vindo de Guanuco e os Piros da região vizinha a Lima" (Erikson, 1998, p. 246).

Os dados arqueológicos mostram que Cumancaya entrou em decadência por volta do ano 1000, quando os Pano reassumem o controle da região do Ucayali até cerca de 1300 e quando a chegada maciça dos Tupi da tradição Miracanguera, antepassados dos atuais Cocama, faz com que os Pano (os antepassados dos grupos Capanawa, Kaxinawa, Shetebo, Shipibo, Jaminawa) recuem para os afluentes do Ucayali. Essa dinâmica entre os Pano, os Arawak e os Tupi passou por momentos diversos até a chegada dos brancos, cuja influência marcante na ocupação da região determinou gradativamente a atual condição e a localização dos povos indígenas.

Segundo Renard-Casevitz (1998, p. 202), as fronteiras amazônicas entre os Arawak subandinos e os Pano apresentavam muitos encavalamentos criados "por sistemas de integração comercial, política e matrimonial que iam unindo todos os componentes do conjunto Arawak e alguns deles a seus vizinhos Pano". A área Pano compunha-se de grupos ribeirinhos que, junto com os Arawak, formavam um sistema de produção de objetos para comércio. Havia outros grupos do interflúvio, sujeitos a ataques pano e arawak e mantidos fora das redes de comércio e cooperação. Essa associação que, ao mesmo tempo, cria a aliança mas mantém a diferenciação linguística e cultural parece permanecer até hoje, como veremos adiante na análise da relação entre os Arawak Manchineri (no Brasil) e Piro-Yine (no Peru) e os Pano Jaminawa ou Yaminawa (Brasil, Peru e Bolívia). 


\section{A incorporação dos povos indígenas da região ao sistema de exploração da borracha}

O processo de colonização da região, impulsionado de início pela exploração das "drogas do sertão" e depois pela exploração da borracha, teve sérias consequências para seus primeiros habitantes. Primeiro houve o choque epidemiológico, provocando enorme mortandade e profunda desestruturação social e psicológica, que multiplicava e estendia o efeito das doenças. Depois, os ataques escravagistas através das "correrias" e das entradas catequéticas. Segundo Menendez (1998, p. 289): "a catequese provocou grande movimentação nas populações indígenas, não só pelos descimentos, concentrando num mesmo aldeamento indivíduos oriundos de grupos diversos, mas também porque muitos indígenas, abandonando as missões, se reagrupavam em locais diferentes das aldeias de origem". Esse reagrupamento muitas vezes promovia a formação de novas entidades coletivas de composição étnica ampliada e transformada. Além disso, os indígenas eram atraídos de forma irresistível pelas ferramentas de metal, cuja introdução era habilmente manipulada pelos missionários e pelos outros agentes, de forma a estabelecer a dependência e a submissão.

Por outro lado, em vários momentos, certos grupos colaboravam com os colonizadores, em parte como estratégia de sobrevivência, ou para conseguir ferramentas, ou ainda para se fortalecer em lutas internas ou contra outros grupos indígenas. Nesse papel, forneciam o grosso das tropas usadas pelos colonos e missionários para capturar escravos e seus neófitos. A conjugação desses efeitos também alterava os circuitos de troca tradicionais, muitas vezes interrompidos pelas migrações forçadas, pelo medo das epidemias (Taylor, 1998, p. 221).

A reação indígena mais comum foi adotar uma "estratégia de crise": a suspensão das trocas, a dispersão e a fuga para zonas-refúgio. $\mathrm{O}$ isolamento, tentando uma independência a qualquer custo, mas ao preço de um empobrecimento cultural e de uma "arcaização" deliberada. Outras vezes ocorria a dissolução étnica por fuga e transculturação individual; ou, o que foi o destino da maioria dos grupos sobreviventes, transformavam-se em coletivos organizados social, econômica e politicamente pela relação de exploração nas mãos dos colonizadores. Constituíam uma formação sociocultural que escondia as filiações culturais específicas em prol de uma identidade fluída e instável, homogeneizada a partir de fora, usando uma língua geral (cf. Taylor, 1998, p. 222) como o português ou o espanhol regional, mas mantendo camufladas suas línguas específicas, alimentadas pela chegada constante de novos refugiados. É a manutenção de uma indianidade específica, ainda que oculta, que distingue esse tipo de formação das populações de ribeirinhos típicas da Amazônia, que em muitos aspectos apresentam um modo de vida muito semelhante ao dos indígenas subjugados. Além isso, desapareceram muitos dos povos citados pelos viajantes e exploradores. No início do século XX, as menções aos índios já são notícias de sua desdita.

Quem sobe o Purus contemplando de longe em longe até as cercanias da Cachoeira, os Pamaris rarescentes, mal recordando os antigos donos daquelas várzeas; e dali para montante os Ipurinãs inofensivos; ou a partir do Iaco, os tucurinas que já nascem velhos, tanto se lhes reflete na compleição tolhiça a decrepitude da raça - tem a maior das surpresas ao deparar, nas cabeceiras do rio, com os silvícolas singulares que as animam. Discordes nos hábitos e na procedência, lá se comprimem em ajuntamento forçado; os amauacas mansos que se agregam aos puestos dos extratores do caucho; os coronauas indomáveis, senhores das cabeceiras do Curanja; os Piro acobreados, de rebrilhantes dentes tintos de rena escura que lhes dão aos rostos, quando sorriem, indefiníveis traços de ameaças sombrias; os barbudos cashillos afeitos ao extermínio em correrias de duzentos anos sobre os destroços das missões do Pachiteá; os Conibos de crânios deformados e bustos espantadamente listrados de vermelho e de azul; os Setebos, Sipibos e Yurimauas; os Mashcos corpulentos, do Mano, evocando no desconforme da estrutura os gigantes fabulados pelos primeiros cartógrafos da Amazônia; e, sobre todos, suplantando-os na fama e no valor, os Campas aguerridos do Urubamba... A variedade das cabildas em área tão reduzida trai a pressão estranha que as constringe. $\mathrm{O}$ ajustamento é forçado. Elas estão, evidentemente, nos últimos redutos para onde refluíram no desfecho de uma campanha secular, que vem do apostolado das mainas às expedições modernas e cujos episódios culminantes se perderam para a História. A civilização, barbaramente armada de rifles fulminantes, assedia completamente ali a barbaria encontrada; os peruanos pelo ocidente e pelo sul; os brasileiros em todo o quadrante NE; no de SE, trancando o vale do Madre-de-Dios, os bolivianos. E os caucheiros aparecem como os mais avantajados batedores da sinistra catequese a ferro e fogo, que vai exterminando naqueles sertões remotíssimos os mais interessantes aborígenes sul-americanos. (Cunha, 2000, p. 160)

Todos esses povos citados são subgrupos Pano (Amauaca, Conibo, Sipivo, Sama, Coronaua e Jaminaua) e Arawak (Piro, Campa), incorporados ao sistema da borracha. Outro desses grupos, de tradição 
arawak, são os Iñapari, descritos por Stiglich (1907), assim como por Hassel (1905), no início do século $\mathrm{XX}$, como uma tribo errante e em vias de desaparição, com apenas 50 indivíduos, na zona de fronteira trinacional Brasil, Bolíva e Peru e dos quais hoje não resta mais nenhum. Outros grupos também se extinguiram. Assim relata Castelo Branco (1950, p. 14) a situação no alto rio Iaco:

Avelino de Medeiros Caves foi auxiliado pelos Catianas, Canamaris e outras tribos na exploração dos seus vastos seringais no alto Iaco mas, à proporção que os serviços se iam alargando, chegaram novos colonos e entre estes alguns maus elementos que provocaram o desaparecimento dos indígenas. [...] desavenças entre as duas raças resultou em alguns lugares, verdadeiras caçadas contra os índios, como aconteceu no alto Iaco, no princípio deste século, em que, sob a chefia de João Alves Vieira, dono do seringal Olinda, foi organizada uma batida contra os Catianas, deixando espalhadas nas margens do rio dezenas de cadáveres, salvando-se algumas mulheres que se refugiaram em outro seringal.

Com a crise da borracha a partir de 1912 e a interrupção da busca de mão de obra nordestina, intensificou-se ainda mais o trabalho indígena. Estes, descaracterizados de suas formas específicas de vida, passaram a ser classificados e discriminados como "caboclos". Os seringais, espalhados ao longo dos rios, sedimentaram-se como unidades de dominação sobre as aldeias. Sua estratégia eram as "correrias", nessa época multiplicadas no intuito de escravizar ou mesmo dizimar os indígenas tanto no Acre quanto nas áreas fronteiriças amazônicas da Bolívia e do Peru. Entretanto, surgiram focos de resistência. Pequenos grupos conseguiram se refugiar nas cabeceiras isoladas, e a maioria foi obrigada a se modificar para não desaparecer. Passaram a adotar o modelo de casa do "branco", a manipular ferramentas, a deixar de usar a língua materna, comunicando-se através do português e do espanhol. Esse processo se aprofundou de tal forma que alguns grupos desapareceram, enquanto outros, mimetizados em "caboclos", viviam espalhados nos seringais da região, vivendo clandestinamente sua indianidade.

De fato, os indígenas passam a mostrar-se como povos singulares só após a década de 1960, quando a queda dos preços da borracha promoveu a desativação dos seringais e com a chegada de criadores de gado sulistas, os chamados "paulistas", ao longo da década de 1970. Os desmatamentos e as tentativas de expulsão dos seringais promoveram a reação de seus habitantes, entre eles os indígenas, alimentando um processo de retomada de sua identidade étnica.

\section{As populações indígenas da fronteira}

Os indígenas na fronteira são uma presença permanente e ambígua. Eles são personagens presentes nas histórias de vida dos habitantes locais e na história da colonização da região da tríplice fronteira, sobretudo os indígenas amazônicos, antigos inimigos, depois tornados caboclos e também seringueiros, como todos, e atualmente reincorporados em suas identidades indígenas específicas. A sobreposição das identidades nacionais que marca essa região de fronteiras muitas vezes escamoteia uma identidade indígena que, em outras circunstâncias, costuma ser a principal. É o caso, por exemplo, das populações migrantes seja dos Andes, seja dos primeiros habitantes de Bolpebra vindos do sul da Bolívia, de língua quechua. Outras vezes, indígenas Yiné, do Peru, são identificados e se identificam como peruanos quando no Brasil. Ou, ao contrário, indígenas manchineri ou jaminawa podem ser identificados como brasileiros quando no Peru ou na Bolívia, instrumentalizando uma identificação que encobre a indígena. No dia a dia das três cidades fronteiriças, é comum ouvir-se o português e o espanhol, além de haver os falantes das línguas dos grupos indígenas presentes, seja o quechua, o manchineri, o jaminawa ou até mesmo o guarani.

No cotidiano das três cidades, entretanto, os indígenas amazônicos são vistos pelos outros habitantes com uma certa reserva, como se vivessem num espaço próprio, delimitado por suas características culturais e suas relações internas. Estes, entretanto, se comunicam com os "de fora" para atos sociais específicos e limitados, sem que, nessa interação social, deixem de ser vistos explicitamente como indígenas, como gente diferente, sobre a qual permanecem vários estereótipos que alimentam essa relação de estranheza dos não índios com relação aos índios. Podemos vêlos fazendo compras no comércio local, sentados em bancos da praça de Assis Brasil ou no abrigo do ponto de ônibus, locais em que os "brancos" não param quando lá estão os índios. Por vezes, encontramos grupos de jovens em discotecas em Iñapari ou em Assis Brasil; ou famílias indígenas misturam-se ao público na festa anual da praia do rio Acre, mas sempre sendo observados e percebidos como "os indígenas", identificação que estabelece certo distanciamento e desconforto.

Em Bolpebra, podem ser vistos já no caminho de entrada na vila, em casas toscas, quase acampamentos, na beira do rio Acre, como é o caso de famílias jaminawa e também manchineri. Ou já em situação mais estável, em casas doadas pela prefeitura, caso de algumas famílias manchineri. 
Além disso, principalmente no lado brasileiro, há os indígenas empregados nas instituições governamentais locais, como o coordenador de saúde indígena da Fundação Nacional da Saúde (Funasa) ou o chefe local da Fundação Nacional do Índio (Funai), assim como professores indígenas em visita à cidade, que se reúnem em sala específica da Secretaria Estadual de Educação.

Os atuais indígenas amazônicos da tríplice fronteira, de filiação linguístico-cultural Arawak, são conhecidos no Brasil como Manchineri e aqueles de filiação linguístico-cultural Pano são conhecidos como Jaminawa. Na Bolívia, são chamados de Machineri e Yaminahua e, no Peru, os de filiação Arawak são nomeados Piro/Yine e os de filiação Pano, Yaminawa.

\section{Manchineri}

Steward (1949) classificava os Manchineri entre os grupos do Juruá-Purus, com características da cultura da floresta tropical, localizando-os entre as bocas do rio Iaco e do rio Araçá (Chandless), assim como no rio Caspahá e no rio Maloca, afluente do alto rio Acre. Hoje há um consenso (Gow, 2002, p. 150-157; Virtanen, 2007, p. 54) de que os atuais Manchineri são membros do grupo Arawak pré-andino composto pelos Piro, Apurinã, Ashaninka, Manchiguenga e Yanesha.

Os Manchineri e os Piro são muito próximos linguística e culturalmente, tendo-se originado dos seguintes grupos ancestrais: os Kochitsineru (povo do pássaro pequeno), Hahamluneru (povo do baixo curso do rio), Hijwutatuneru (povo da boca do rio), Wenezeru Himnuneru (povo sapo), Nastineru (povo faminto), Cocamolineru (povo picapau), Getuneru (povo cobra), Pleneru (povo arara) e Mayineru (povo da árvore Inharé) (cf. Virtanen, 2007 e entrevistas com os Manchineri de Assis Brasil, realizadas em 2008).

Os Manchineri atuais têm diferentes explicações para os diversos subgrupos. Uns dizem que esses subgrupos eram divisões cerimoniais num passado distante; outros afirmam que eram grupos que migraram de lugares diferentes e passaram a estabelecer alianças através de casamentos, na época em que os exploradores da borracha chegaram à região. Os Piro são vistos pelos Manchineri como descendentes desses mesmos grupos, em especial do Kochitsineru (pássaro pequeno). Dizem que os Piro adquiriram esse nome no tempo dos barões da borracha, por suas tentativas mal-sucedidas de pronunciar "Peru", quando queriam afirmar-se peruanos para evitar mais conflitos.

Steward \& Metraux (1948) localizam os Piro no alto Ucayali, Tambo e Urubamba. Outros auto- res (Matteson, 1965; Gow, 1991) atestam que os Piro também eram divididos nos mesmos grupos nominados dos quais provêm os Manchineri. Por outro lado, há vários Manchineri que afirmam que os vários grupos "neru", hoje chamados de Manchineri no Brasil e Piro no Peru, seriam parcialidades de uma grande etnia que eles denominam Yine, cujo significado seria "nós, o povo". Assim também nos informaram os habitantes Piro/Manchineri/Yine da comunidade Nativa Bélgica, localizada no Peru, quando os visitamos em julho de 2008. Alguns Manchineri da T.I. Mamoadate e outros em Assis Brasil confirmam essa versão: o nome Manchineri é uma corruptela de Maniteneru ou de outro desses subgrupos, nomes que os brancos não conseguiam pronunciar direito.

De meados do século XIX até a primeira década do século XX, vários grupos Manchineri, assim como os Jaminawa e outros povos, foram cercados pelas frentes de expansão do caucho e da seringa. Em certos momentos resistiram, lutando contra os invasores, em outros fugiram, indo para áreas mais isoladas. Muitos foram escravizados, aliando-se forçadamente aos colonizadores e trabalhando como guias, remadores ou seringueiros. Esse era o tempo das "correrias".

Finalmente, todos subjugados, agregados ao trabalho nos seringais no sistema de "aviamento", desindianizados e sem direitos foram transformados em "caboclos". Vivendo em terras possuídas pelos seringalistas, sempre endividados pelo preço superinflacionado de bens (comida, ferramentas, roupas etc.) fornecidos pelos "patrões", a eles davam toda a produção, escravizados por uma dívida que jamais poderia ser paga. Aprenderam o português e adotaram um modo de vida não indígena. Muitas vezes eram pagos apenas em mercadorias e em bebida alcoólica, a famosa cachaça, o que introduziu entre eles a prática da embriaguez e muitas vezes o alcoolismo. Esse foi o tempo de "cativeiro", que perdurou até meados da década de 1970.

A década de 1970 foi marcada por vários processos convergentes, abrindo mais espaço político afirmativo para os povos indígenas. Houve uma mudança acentuada na orientação da Igreja Católica a partir de 1960 e, no Brasil, ocorreu a criação do Conselho Indigenista Missionário (CIMI) em 1972, que imprimiu um novo estilo no trabalho com os indígenas, com base no respeito cultural e na defesa da terra. Fundaram-se em vários locais organizações em defesa dos povos indígenas, as comissões pró-índio. A Antropologia fez sua autocrítica na reunião dos americanistas, em Barbados, em 1970, assumindo postura mais combativa e de denúncia (Arruda, 1992).

Foi nesse contexto que, a partir de notícias da existência de indígenas no Acre (que eram dados como extintos) vivendo como que escravizados nos 
seringais, a Funai abriu um escritório em Rio Branco em 1976 e passou a verificar a situação dos indígenas no estado do Acre.

Os primeiros relatórios da Funai no Acre apontam os Manchineri e os Jaminawa vivendo como seringueiros nos seringais Guanabara e Petrópolis e em vários lugares do rio Iaco e do rio Acre, tanto no lado brasileiro como no lado peruano. Assim, em 1977, a Funai abriu um posto indígena no igarapé Extrema, realizando a identificação ${ }^{1}$ da área indígena Mamoadate, para onde passaram a ser transferidos os Manchineri e os Jaminawa. Começou aí o que chamam de o tempo "dos direitos".

Os índios escolheram o local, um dia rio acima do Seringal Petrópolis, denominado Extrema para implantação do PI, de suas moradias e roças. A escolha deste local se deveu principalmente por se tratar de antiga maloca de Machineri [...]. Iniciamos o trabalho com poucas famílias pois muitos não acreditavam ainda na atuação da Funai. [...] Foi construído o PI, barracão, depósito, escola, campo de pouso com 700 $\mathrm{m}$ e desmatamento da cabeceira da pista. Paralelamente a isso todos que lá foram trabalhar fizeram suas roças e casas. [...]. A população foi aumentando espontaneamente e vem aumentando até hoje. [...] Era um "parente" que chegava hoje, trabalhava livre de pressões, fazia sua roça e casa no lugar que mais lhe agradasse, via caça e peixe com fartura, via sua roça crescer sem ser estragada por bois e voltava para buscar o resto dos "parentes" mais chegados. (Meireles Jr., 1978)

Ainda assim, parte dos Manchineri permaneceu nos lugares que já vinham ocupando, fora dos limites da terra indígena Mamoadate. Famílias se mantiveram no seringal Guanabara, área reivindicada por eles como terra indígena, e também na área que hoje é a reserva extrativista Chico Mendes, onde vivem alguns Manchineri e Jaminawa, no trecho confrontante com a Comunidad Nativa de Bélgica, no Peru, situada na outra margem do rio Acre.

No lado peruano, na Comunidad Nativa de Bélgica (53.300 hectares), vivem 16 famílias, cerca de 90 pessoas. Sua autodenominação oficial é Yiné, identidade compartida frouxamente por seus habitantes. Alguns se dizem alternativamente Piro; há quatro irmãos, com suas famílias, que vieram do rio Tihuamanu, onde trabalhavam numa madeireira, que se autodenominam Manchineri. A mãe do presidente da Comunidad, dona Cacilda, conta que ela e seus filhos nasceram no lado brasileiro, mas vieram para o Peru para trabalhar no seringal Bélgica. Atualmente, ela é casada com um Jaminawa, com quem vive na outra margem do rio Acre, no território brasileiro, na Resex Chico Mendes.

Além dos indígenas dessa Comunidad Nativa, há outro grupo Yine na Comunidad Nativa de Oceania, perto de Ibéria, formada por um grupo de 25 famílias que se separou da Comunidad de Bélgica cerca de 15 anos atrás, por motivo de um conflito interno.

$\mathrm{Na}$ Bolívia vivem cerca de seis famílias manchineri em Bolpebra, e outras na "Tierra Comunitária de Origen Yaminahua-Machineri", localizada no cantão Mudken. É uma área de 41.920,5928 hectares, sendo habitada por uma população flutuante de cerca de 12 famílias. $^{2}$ É na Bolívia também que se formou a Central Indígena de Pueblos Originários de Pando (Cipoap), organização que representa as comunidades dos povos Tacan, Cavineño, Ese Ejja e os povos Yaminahua e Machineri. Além desta existe a Organización Yaminahua-Machineri (Oyama).

\section{Jaminawa}

Jaminawa é o nome genérico atribuído a um conjunto de grupos/povos/identidades/ da família linguística Pano. É, assim como em relação aos Manchineri, um termo "jurídico" e uma identidade construída nesse processo histórico de submetimento à dinâmica de expansão dos Estados nacionais.

O nome foi incorporado por eles e, como nos afirmou José Correia Tunumã, uma das lideranças mais atuantes na história contemporânea dos Jaminawa, "por um lado até que foi bom, pois ajudou para unir um pouco mais esses povos e facilita nossas lutas".

Mas os assim chamados Jaminawa compõem-se de várias parcialidades, cuja funcionalidade estrutural parece não operar mais atualmente, devido ao desconhecimento pelas gerações mais jovens da genealogia do grupo e às transformações do seu modo de vida. Seriam povos distintos, ou operariam como clãs?

De acordo com Calavia (1995), os Jaminawa se dividem em um número indeterminado de kaio, que seriam clãs de caráter "totêmico" e de linha paterna. O conjunto de kaio tende a coincidir diversos etnônimos, sendo os principais os Xixinawa (gente do qua-

1 A "identificação" de uma área indígena, definindo inicialmente um perímetro e interditando a área para não indígenas, é o primeiro passo para sua regularização definitiva pelo Estado brasileiro. Após esse procedimento, a terra indígena Mamoadate foi demarcada em 1986, com uma superfície de 313.647 ha e perímetro de 336 km, tendo sido registrada no CRI e SPU em 1987.

2 Mancomunidad Unión Amazónica Filadelfia-Bolpebra/Esperanza Chávez de los Rios. Plan Municipal de Ordenamiento Territorial de la Mancomunidad Unión Amazónica Filadelfia-Bolpebra. Proyeto Bosque y Vida. Santa Cruz, Bolívia, 2006. 
ti); Kununawa (gente da orelha de pau); Sharanawa; Mastanawa; Kaxinawa e outras diversas parcialidades. Portanto, os Jaminawa só existem como pluralidade. Os Jaminawa, por sua vez, estendem o nome Jaminawa para além dos grupos Pano do rio Purus, englobando também os Kaxinawá e vários grupos do rio Juruá.

Foram encontrados, junto com os Manchineri, nos seringais Guanabara e Petrópolis, sendo transferidos para a terra indígena Mamoadate, de onde parte deles, por desavenças internas, voltou para o rio Acre em 1987, ocupando a área que hoje constitui a TI Cabeceira do Rio Acre. ${ }^{3}$

O relatório de identificação da TI Mamoadate refere-se ao movimento da população Jaminawa pelas cabeceiras dos rios Acre, Iaco e Chandless. Além deste, o relatório de Espírito Santo (1992, p. 4) descreve sua movimentação nas décadas de 1960 a 1980:

Habitavam uma aldeia localizada em terras brasileiras, no rio Acre próximo à foz do igarapé Nicolau que nasce no Peru [...]. Por volta de 1962 abandonaram essa aldeia por causa de uma epidemia de sarampo, evitando a convivência com os espíritos dos mortos que permanecem no local. Foram estabelecer-se no igarapé Patos, afluente do rio Acre. Passaram a trabalhar para Coriolano, ligado ao dono do Seringal São Francisco, Benedito Batista, na extração do caucho, madeira e peles. Em 1966, de volta das cabeceiras do rio Chandless onde foram visitar parentes, passaram pelo rio Iaco (atual TI Mamoadate) onde os Manchineri trabalhavam para Canízio, dono do Seringal Petrópolis, e resolveram ficar, em face das boas possibilidades de aquisição de mercadorias fornecidas pelo seringal na época. Quando em 1969 ocorre nova epidemia de sarampo, parte desse grupo indígena, liderado por Antonio Jaminawa, retorna ao rio Acre, onde haviam permanecido algumas famílias Jaminawa, estabelecendo-se no local conhecido por São Lourenço, na foz do igarapé do mesmo nome. $\mathrm{O}$ alto rio Acre, por ser uma região mais isolada, era considerado um local seguro contra as doenças transmitidas pelos não índios. Apesar das constantes desavenças entre os Jaminawa e Manchineri, o grupo dos Jaminawa que permaneceu no Iaco engajou-se na luta pela demarcação da área conhecida como Mamoadate. Aparece como liderança desse grupo José Correia da Silva, que em 1987 sai com os demais de volta para o rio Acre, estabelecendo-se no local conhecido por Ananaia. O motivo do retorno se deveu a novos desentendimentos com os Manchineri e a falta de assistência ao Jaminawa, que se sentia discriminado dentro da área Mamoadate.
Atualmente os Jaminawa se distribuem por algumas localidades no estado do Acre, no Brasil; no departamento de Pando, na Bolívia, e no departamento de Tahuamanu, no Peru. No lado brasileiro, têm aldeias na terra indígena Mamoadate, no rio Iaco, onde há também aldeias manchineri, e na terra indígena Cabeceiras do rio Acre, ambas no município de Assis Brasil. Ocupam também diversos seringais próximos a esses dois rios, sendo Guajará o principal deles, e também no rio Caeté. Há também famílias Jaminawa na T.I. Alto Rio Purus, nos municípios de Manoel Urbano e Santa Rosa. As terras ocupadas e reivindicadas pelos Jaminawa e pelos Manchineri encontram-se em diferentes estágios do processo de regularização fundiária, conforme podemos ver na Tabela 1, mas não esgotam seus atuais locais de ocupação.

Além dessas áreas, há famílias Jaminawa vivendo em Rio Branco, capital do Acre, e também no bairro Samaúma, na cidade de Brasileia. Acresce-se a essas localidades a aldeia Jaminawa na cidade de Assis Brasil, um conjunto contínuo de casas ao longo do rio Acre no caminho para Iñapari, no Peru. Ali vivem famílias que dividem seu tempo entre Assis Brasil e suas aldeias na T.I. Cabeceiras do Acre; de população flutuante, de moradia sazonal para os que têm afazeres em Assis Brasil. Há também algumas famílias Jaminawa vivendo em Bolpebra, na outra margem do rio Acre - no momento (julho de 2008), vivem de mantimentos trazidos de roças de aldeias localizadas na Bolívia (aldeia Guajará e aldeia São Pedro, na margem boliviana do rio Acre, no interior da Tierra Comunitária de Origen Machineri-Jaminahua), do pescado eventual no rio Acre e de alguma renda monetária dos homens que trabalham para uma madeireira boliviana. Sua presença ali parece ser recente (em abril de 2007 já viviam ali) e têm apoio da prefeitura de Bolpebra, que lhes permitiu a construção de casas. As crianças estudam na escola municipal. Em Assis Brasil, além do "bairro Jaminawa", há cerca de 50 Manchineri vivendo permanentemente na cidade, além de, assim como os Jaminawa, haver uma visitação constante à cidade de famílias que vivem nas aldeias das terras indígenas mais próximas: para receber suas aposentadorias e fazer compras, visitar os parentes urbanos, participar de festas regionais, tais como a festa da praia realizada no final do mês de julho.

Uma característica marcante dos Jaminawa é seu seminomadismo, manifesto desde as primeiras notícias que se tem sobre eles e que se revela hoje nas frequentes mudanças de localização das aldeias e das casas, na dinâmica de alternância entre tempos de vivência nas cidades e nas aldeias e na frequente fixação em lugares novos. Quanto a isso, as fontes históricas 
Tabela 1 - Relação das terras indígenas jaminawa e manchineri na tríplice fronteira

\begin{tabular}{|l|r|r|l|l|l|}
\hline $\begin{array}{l}\text { Terra indígena } \\
\text { Povo }\end{array}$ & População & $\begin{array}{c}\text { Extensão } \\
\text { (ha) }\end{array}$ & Município & País/UF & Situação jurídica \\
\hline $\begin{array}{l}\text { Alto Rio Purus } \\
\text { (Kaxinawá/Kulina/Jaminawa) }\end{array}$ & 1.691 & 263.130 & $\begin{array}{l}\text { Manoel Urbano } \\
\text { Sta. Rosa }\end{array}$ & BR/AC & Registrada (CRI-DPU) \\
\hline $\begin{array}{l}\text { Cabeceira do Rio Acre } \\
\text { (Jaminawa) }\end{array}$ & 450 & 78.512 & Assis Brasil & BR/AC & Registrada (CRI-DPU) \\
\hline $\begin{array}{l}\text { Jaminawa/Arara do Rio Bagé } \\
\text { (Arara Shawanauá e Jaminawa) }\end{array}$ & 315 & 28.926 & Marechal Taumaturgo & BR/AC & Registrada (CRI-DPU) \\
\hline $\begin{array}{l}\text { Jaminawa da Colocação São Paulino } \\
\text { (Jaminawa) }\end{array}$ & 46 & -- & $\begin{array}{l}\text { Boca do Acre } \\
\text { Sena Madureira }\end{array}$ & $\begin{array}{l}\text { BR/AC } \\
\text { AM }\end{array}$ & A identificar \\
\hline $\begin{array}{l}\text { Jaminawa do Guajará } \\
\text { (Jaminawa) }\end{array}$ & 70 & 600 & Sena Madureira & BR/AC & A identificar \\
\hline $\begin{array}{l}\text { Jaminawa / Igarapé Preto } \\
\text { (Jaminawa) }\end{array}$ & 160 & 25.651 & Rodrigues Alves & BR/AC & Registrada (CRI-DPU) \\
\hline $\begin{array}{l}\text { Jaminawa do Rio Caeté } \\
\text { (Jaminawa) }\end{array}$ & 66 & -- & Sena Madureira & BR/AC & A identificar \\
\hline $\begin{array}{l}\text { Jaminawa do Seringal São Francisco } \\
\text { (Jaminawa) }\end{array}$ & 73 & -- & Sena Madureira & BR/AC & Sem providências \\
\hline $\begin{array}{l}\text { Mamoadate } \\
\text { (Jaminawa e Manchineri) }\end{array}$ & 576 & 313.647 & $\begin{array}{l}\text { Sena Madureira } \\
\text { Assis Brasil }\end{array}$ & BR/AC & Registrada (CRI-DPU) \\
\hline $\begin{array}{l}\text { Seringal Guanabara } \\
\text { (Manchineri) }\end{array}$ & 92 & -- & Assis Brasil & BR/AC & A identificar \\
\hline $\begin{array}{l}\text { Comunidad Nativa Bélgica } \\
\text { (Yiné/Piro/Manchineri) }\end{array}$ & 90 & 53.300 & Iñapari & $\begin{array}{l}\text { Tahuamanu } \\
\text { Peru }\end{array}$ & Saneada \\
\hline $\begin{array}{l}\text { Tierra Comunitaria de Origen } \\
\text { Yaminahua - Machineri } \\
\text { (Jaminawa e Manchineri) }\end{array}$ & $\begin{array}{l}\text { Pando } \\
\text { Bolivia }\end{array}$ & Saneada \\
\hline
\end{tabular}

Fonte: Funai (12/9/2005), Diretoria de Assuntos Fundiários; Mancomunidad Union Amazónica Filadelfia - Bolpebra (2006).

já referidas mostram um processo de dispersão constante causado pela ocupação de seus territórios pela exploração do caucho do lado peruano e boliviano e pelos seringais do lado brasileiro. Por outro lado, relatórios mais recentes da Funai e de pesquisadores apontam uma constante mudança não só de lugares, mas fundamentalmente da composição dos grupos. Os deslocamentos Jaminawa, na verdade, correspondem a processos de cisão, em função de tensões e brigas internas ou de conflitos abertos com grupos vizinhos. Vistos em conjunto, todavia, a ocupação constante de novos lugares aparece também como um alargamento de seus territórios, uma ampliação de interlocutores e parceiros na sociedade nacional, constituindo uma estratégia de resistência e de luta por maior autonomia. A emergência do movimento indígena no Brasil a partir da década de 1970 proporciona, nos anos 80 , a criação da União das $\mathrm{Na}$ ções Indígenas do Acre e Sul do Amazonas (Uniacre), organização com sede em Rio Branco, capital do Acre. Os Jaminawa e os Manchineri estão desde o início ligados ao movimento e alguns de seus membros ocuparam cargos de direção da entidade. Dessa forma, um grupo de Jaminawa passou a morar em Rio Branco, acompanhando suas lideranças ligadas à Uniacre.

De fato, nos últimos anos tem ocorrido uma certa migração de indígenas para as cidades, tanto para Rio Branco quanto para as cidades da tríplice fronteira. Essa migração relaciona-se com as lutas por maior autonomia, com as tentativas de ocupar cargos estratégicos que permitam um melhor posicionamento nas lutas por seus direitos e interesses. Assim, o movimento indígena passou também a lutar pelos interesses indígenas no interior do aparelho do Estado, em especial na Fundação Nacional do Índio, hoje dirigida no estado do Acre por Antonio Apurinã. Ao longo do tempo conseguiram ocupar vários cargos no órgão e, em 2008, tanto os chefes de postos como os administradores locais já eram indígenas. Do mesmo modo, empregos na Fundação Nacional de Saúde (Funasa) e na prefeitura de Assis Brasil, a disputa por cargos eletivos nas eleições municipais e outras tantas iniciativas e movimentações em curso são a motivação para a migração para as cidades.

Entretanto, vale enfatizar, a ida para as cidades não corta os laços com as aldeias nem desfaz a identidade indígena. Seu sentido é o de maior participação como indígena na sociedade nacional. Esse movimento corresponde, no plano das aldeias e terras indígenas, à criação das associações: uma face jurídica para a captação de recursos e o desenvolvimento de projetos. Além das associações de caráter nacional e regional, das quais os povos indígenas da região participam, há associações locais, que representam seus interesses mais específicos (Tabela 2). 
Tabela 2 - Relação das associações indígenas manchineri e jaminawa na região da tríplice fronteira

\begin{tabular}{|l|l|c|l|l|}
\hline Nome da Associação & Sigla & $\begin{array}{c}\text { Ano de } \\
\text { fundação }\end{array}$ & Terra indígena/Povo & Município \\
\hline $\begin{array}{l}\text { Organização Comunitária Agroextrativista } \\
\text { Jaminawa }\end{array}$ & OCAEJ & 2001 & Jaminawa do Rio Caeté & Sena Madureira \\
\hline $\begin{array}{l}\text { Associação do Povo Jaminawa Arara (Chave } \\
\text { do Futuro) }\end{array}$ & 2002 & Jaminawa-Arara do Rio Bagé & Marechal Thaumaturgo \\
\hline $\begin{array}{l}\text { Manxineryne Ptohi Kajpa Hajene } \\
\text { (Organização do Povo Manchineri do Rio } \\
\text { Iaco) }\end{array}$ & MAPKAHA & 2004 & Mamoadate Manchineri & Sena Madureira \\
\hline $\begin{array}{l}\text { Associação Agroextrativista Manchineri } \\
\text { da Aldeia Jatobá - Rio Iaco }\end{array}$ & AAEMRY & 2004 & $\begin{array}{l}\text { Mamoadate } \\
\text { Manchineri }\end{array}$ & Sena Madureira \\
\hline $\begin{array}{l}\text { Associação Jaminawa e Jaminawa-Arara da } \\
\text { TI Jaminawa do Igarapé Preto. }\end{array}$ & AJJAIP & 2004 & $\begin{array}{l}\text { Jaminawa do Igarapé } \\
\text { Preto }\end{array}$ & Cruzeiro do Sul \\
\hline $\begin{array}{l}\text { Central Indígena de Pueblos Originários } \\
\text { de Pando }\end{array}$ & CIPOAP & OYAMA & $\begin{array}{l}\text { Tierra Comunitaria de Origen } \\
\text { Yaminahua-Machineri }\end{array}$ & San Pedro de Bolpebra \\
\hline Organización Yaminahua-Machineri & Cobija \\
\hline
\end{tabular}

Fonte: SMA (Secretaria de Meio Ambiente do Estado do Acre), 2003; Mancomunidad Union Amazónica Filadelfia - Bolpebra (2006).

\section{Fronteiras, identidades nacionais e identidades indígenas}

A formação dos países e etnias, identidades demarcadas por múltiplas fronteiras, dá-se no contexto colonial, dentro de cuja moldura se submetem os grupos étnicos em processos de territorialização (cf. $\mathrm{Pa}-$ checo de Oliveira, 1998) em boa parte moldados por esse submetimento. $\mathrm{O}$ que não significa a passividade dos grupos étnicos, mas apenas seu constrangimento num campo social marcado pela presença dominante do Estado-nação. É nessa moldura que o Estado cria os recortes sociológicos que acabam incorporando e sendo incorporados pelos povos indígenas.

Os povos indígenas da região foram sendo "identificados" num contexto de perda demográfica, de acentuação de conflitos internos e entre grupos diferentes, de deslocamentos e perdas territoriais. À medida que a colonização se adensava, grupos indígenas foram sendo isolados de seu contexto mais amplo de sociabilidades regionais, todas elas passando a ser mediadas pelo Estado e por grupos religiosos. Formou-se assim um plano das dinâmicas sociais locais, de um sistema de fronteira, de culturas e de redes de sociabilidade de fronteira, expressão das relações de aliança, de comércio, de convivência e também de disputas entre as populações que ali viviam e vivem ainda hoje. E outro plano, o das políticas de Estado, que obedecem a lógicas mais amplas e interesses variados, procurando tanto legitimar interesses locais quanto impor seus próprios interesses e políticas no local.

Observa-se aqui uma reorganização e uma recomposição de sujeitos coletivos conformados por uma milenar história cultural que, no contexto dos processos de colonização dos últimos dois séculos, procuram se acomodar nas novas formas de existir no mundo dos Estados-nação. Para esses povos, a tríplice fronteira é, do ponto de vista espacial, uma ficção. Tendo suas populações nos tres países, movimentamse com total liberdade de um lado para o outro. Suas relações familiares e de aliança transpassam as fronteiras. Politicamente, as fronteiras e as diferenças legais entre os tres países tornam-se um recurso importante que muita vezes é instrumentalizado.

As legislações do Peru e da Bolívia permitem aos indígenas a exploração sustentável da madeira e de outros recursos, o que é proibido no Brasil. Por outro lado, o Brasil tem melhor assistência à saúde e um sistema de aposentadoria aos trabalhadores rurais, inclusive aos indígenas. Assim, sua movimentação fronteiriça obedece a estratégias e momentos de vida diferentes, nos quais os indivíduos instrumentalizam as identidades de boliviano, peruano e brasileiro, juntamente com suas identidades indígenas. Como nos mostra Valcuende (1995), a mobilidade da população de um a outro lado das fronteiras é uma estratégia habitual, tal como ocorre em outros contextos fronteiriços nos quais as populações locais aprendem a instrumentalizar sua posição liminar para sobreviver.

Concluímos que as classificações legitimadas pelo Estado estabeleceram tanto as fronteiras identitárias quanto o formato identitário que têm guiado as políticas indigenistas e até mesmo os estudos etnográficos regionais. Essas fronteiras étnicas e seu formato identitário têm, além disso, influído no modo de organização desses grupos e do movimento indígena regional. Tanto os Manchineri quanto os Jaminawa formaram sua identidade atual a partir de uma classificação jurídico-antropológica distinta de sua lógica identitária histórica, muito mais variada e mutável. 
Mesmo a criação de "associações indígenas", locais, regionais ou nacionais, são formas sociais novas, instrumentalizações indígenas da sociedade nacional. $\mathrm{O}$ Estado-nação é a "comunidade imaginada", como bem o definiu Anderson (1989), e o mesmo se pode dizer das etnias, artefato cultural cuja existência nesse modelo identitário se constitui ao mesmo tempo associado, subordinado e contraposto ao Estado-nação.

\section{Referências}

ACUÑA, Padre Cristobal de. Descobrimento do rio das Amazonas. São Paulo: Editora Nacional, 1941. (Biblioteca Pedagógica Brasileira, série 5a , Brasiliana, 203).

ALVES DE SOUZA, Carlos Alberto. História do Acre. Rio Branco: Editor Carlos Alberto Alves de Souza, 2005.

ANDERSON, Benedict. Nação e consciência nacional. São Paulo: Ática, 1989.

AQUINO, Terri Valle de \& IGLESIAS, Marcelo Piedrafita. Zoneamento ecológico-econômico do Acre: terras e populações indígenas. Rio Branco: SEMA, 1999.

ARRUDA, Rinaldo S. V. Os Rikbaktsa: mudança e tradição. 1992. Tese (Doutorado) - PUCSP, São Paulo, 1992.

CALAVIA SAEZ, Oscar. O nome e o tempo dos Yaminawa. 1995. Tese (Doutorado) - USP, São Paulo, 1995.

CAMACHO, Roberto Pineda. La Casa Arana en el Putumayo: el caucho y el proceso esclavista. Revista Credencial Historia, Bogotá-Colombia, Edición 160, abril de 2003.

CARVAJAL, Frei Gaspar de. Relatório do novo descobrimento do famoso rio grande descoberto pelo capitão Francisco de Orellana (1542). São Paulo: Editora Nacional, 1941.

CASTELO BRANCO, José Moreira Brandão. Caminhos do Acre. Revista do Instituto Histórico e Geográfico Brasileiro, v. 196, p. 74-225, 1947.

CASTELO BRANCO, José Moreira Brandão. O gentio acreano. Revista do Instituto Histórico e Geográfico Brasileiro, v. 207, p. 3-78, 1950.

CASTELO BRANCO, José Moreira Brandão. Acreânia. Revista do Instituto Histórico e Geográfico Brasileiro, v. 240, p. 3-83, 1958.

CASTELO BRANCO, José Moreira Brandão. Povoamento da Acreânia. Revista do Instituto Histórico e Geográfico Brasileiro, v. 250, p. 118-256, 1961.

CHANDLESS, William. Notas sobre o rio Purus (lidas perante a Real Sociedade de Geografia de Londres em 26 de fevereiro de 1868). Arquivos da Associação Comercial do Amazonas, v. 9, p. 21-29 e v. 10, p. 29-40, 1949.

COUTINHO JR., Walter. Áreas de ocupação indígena ainda não regularizadas no Acre e sul do Amazonas. Relatório de viagem. Brasília: Funai, 2001.

COUTINHO, João Martins da Silva. Relatório de exploração do rio Purús. Typographia de J. I. da Silva, 1862.

CRUVINEL, Noraldino Vieira \& CARVALHO, José Porfírio F. Jaminaua e Manchineri do alto rio Iaco. Brasília: Funai, 1977.

CUNHA, Euclides da. Um paraíso perdido: ensaios amazônicos. Brasília: Senado Federal, 2000.
CUNHA, Manuela Carneiro da. História dos índios no Brasil. São Paulo: Cia. das Letras, 1998.

DELBOY, Emílio. Conferência dada por el señor Emílio Delboy la noche de 21 de noviembre sobre las regiones del Madre de Dios y Acre. Boletin de la Sociedad Geográfica de Lima, 1912.

ERIKSON, Philippe. Uma singular pluralidade: a etnohistória Pano. In: CUNHA, Manuela Carneiro da. História dos índios no Brasil. São Paulo: Cia das Letras, 1998. p. 239-252.

ESPÍRITO SANTO, Marco Antonio do. Relatório de viagem à área indígena Cabeceira do Rio Acre. Grupo indígena Jaminawa. GT PP. n. 1191/91. Brasília: Funai, 1992.

FUNAI (Fundação Nacional do Índio). Jaminaua e Machineri do alto rio Iaco. Brasília: Núcleo de História Indígena e do Indigenismo, Fundação Nacional do Índio, Ministério do Interior, 1977.

GONÇALVES, M. A. Acre: história e etnologia. Rio de Janeiro: Núcleo de Etnologia Indígena, Universidade Federal do Rio de Janeiro, 1991.

GOW, P. Of mixed blood. Kinship and history in Peruvian Amazonia. Oxford: Clarendon Press, 1991.

GOW, P. Piro, Apurinã and Campa: Social Dissimilation and Assimilation as Historical Process in Southwestern Amazonia. Comparative Arawakan Histories: rethinkink language family and culture in Amazonia. Xxxxxxx: University of Illinois Press, 2002.

HAENKE, Tadeo. Tadeo Haenke, su obra en los Andes y la selva boliviana. Seleccion, prologo y notas de Guillermo Ovando-Sanz. La Paz: Editorial Los Amigos del Libro, 1974.

HASSEL, J. M. Von. Las tribus salvajes de la Región Amazónica del Perú. Sociedade Geográfica de Lima, V.XXI, Lima, 1905.

HAVERROTH, M. Relatório da viagem à terra indígena Mamoadate. Rio Branco: Comissão Pró-Índio/Programa de Saúde Sujo, Limpo \& Contaminado/Capacitação de Agentes de Saúde em Higiene e Saneamento Ambiental e Assistência Primária de Saúde, 1999.

LATHRAP, Donald W. The upper Amazon: anciente peoples and places. London: Thames and Hudson, 1970.

LATHRAP, Donald W; GEBHART-SAYER, A.; MESTER, A. The roots of the Shipibo art style: three waves on Imiriacocha or there were "Incas" before the Incas. Journal of Latin American Lore, v. XI, p. 31-120, 1985.

LOSSIO, Julio. Plazas centrales e intermedias en Madre de Dios: del descubrimiento de Fitzcarrald - 1893 - al 
último censo 1993. Perú: el problema agrario en debate. Seminario permanente de investigación agraria. Sepia Fundación Mac Arthur Grant - Oxfam GB - Consorcio de investigación económica y social - Care-Puno, 2002. p. 550-577.

MATTESON, E. The Piro (Arawakan) Language. Berkeley: University of California, 1965.

MEIRELES JR., José Carlos dos Reis. Os Manchineri e os Jaminaua do rio Iaco. Relatório Funai, Rio Branco, 1978.

MENENDEZ, Miguel A. A área Madeira-Tapajós: situação de contato e relações entre colonizador e indígenas. In: CUNHA, Manuela Carneiro da. História dos índios no Brasil. São Paulo: Cia. das Letras, 1998, p. 281-296.

MYERS, T. P. Visión de la prehistoria de la Amazonia Superior. In: SANTOS, F. (Org.). I Seminário de Investigaciones Sociales en la Amazonía Peruana. Iquitos, Ceta, 1988. p. 37-87.

OLIVEIRA, João Pacheco de (Org.). Indigenismo e territorialização: poderes, rotinas e saberes coloniais no Brasil contemporâneo. Rio de Janeiro: Contra Capa Livraria Ltda., 1998.

RENARD-CASEVITZ, France-Marie. História Kampa, memória Ashaninca. In: CUNHA, Manuela Carneiro da. História dos índios no Brasil. São Paulo: Cia. das Letras, 1998. p. 197-202.

ROE, Peter G. The Josho Nahuanbo are all wet and undercooked: shipibo views of the whiteman and the Incas in myth, legend and history. In: HILL, J. (Org.). Rethinking history and myth: indigenous South American perspectives on the past. Urbana and Chicago: University of Illinois Press, 1998. p. 35-106.

RoOseVELT, Anna Curtenius. Arqueologia Amazônica. In: CUNHA, Manuela Carneiro da. História dos índios no Brasil. São Paulo: Cia. das Letras, 1998. p. 53-86.
SCHULTZ, Harold; CHIARA, Vilma. Informações sobre os índios do alto rio Purus. Revista do Museu Paulista. São Paulo: Nova Série, 1955.

SOARES FILHO, Armando. Relatório da missão de fiscalização na terra indígena Mamoadate. Funai, PIN Assis Brasil, 2002.

STEWARD, Julian H. (Org.). The native population of South America. Handbook of South American Indian. Washington: Smithsonian Institution, Bureau of American Ethnology, 1949, v. 5, p. 655-68.

STEWARD, Julian H.; METRAUX, A. Tribes of the Peruvian and Ecuatorian Montaña. Handbook of South American Indians. Washington: Smithsonian I. Bureau of American Ethnology, Bull, 143, 1949. v. 3, p. 535-656. STIGLICH, G. Junta de las vías fluviales: últimas exploraciones ordenadas por la Junta de Vias Fluviales a los ríos de Madre de Dios, Paucartambo y Urubamba. (Informe de los Sres. Stiglich, Von Hassel, Olivera y Ontaneda). Lima: La Opinión Nacional, 1907.

TAYLOR, Anne Christine. História pós-colombiana da alta Amazônia. In: CUNHA, Manuela Carneiro da. História dos indios no Brasil. São Paulo: Cia. das Letras, 1998. p. 213-238. TOCANTINS, L. Formação histórica do Acre. Rio de Janeiro: Civilização Brasileira, 1979.

VALCUENDE, J. M. Los "Portugueses" del Rio. Actas de las I Jornadas Transfronterizas sobre la Contienda Hispanoportuguesa. Tomo I. Biblioteca de Estudios Arochenos, n. 5, 1995. p. 201-216.

VIRTANEN, Pirjo Kristiina. Changing Lived Worlds of Contemporary Amazonian Native Young People: Manchineri Youths in the Reserve and the City, Brazil-Acre. 2007. Dissertation (Doctoral) - Latin American Studies Renvall Institute for Area and Cultural Studies, University of Helsinki, Finland, 2007. 


\title{
Borders and identities: the Manchineri and the Jaminawa in the triple border Brazil-Bolivia-Peru
}

\begin{abstract}
This article deals with the vicissitudes of people known today as Manchineri and Jaminawa, inhabitants of border regions of the department of Pando, in Bolivia, Madre de Dios in Peru and Acre state in Brazil. It seeks to trace their connections and the relevance of their historical identity as people of Arawak and Pano linguistic and cultural affiliation, to point the process of involvement by the expansion of the national societies of Bolivia, Peru and Brazil, driven by the exploitation of rubber in the region, and finally to show their presently defined political identity and their conditions of life that were shaped by these processes. But even if it is shaped by the involvement and the standardizations of the national territory allocated at national borders, imposing landmarks "legitimate" for the life of its inhabitants, we point out how these indigenous people are intent on equipping try to use these legal and sociocultural parameters that were intended to subdue them.
\end{abstract}

Key words: Manchineri, Jaminawa, borders, identity, nation state, ethnicity.

\section{Las fronteras y las identidades: los Manchineri y los Jaminawa en la triple frontera Brasil, Bolivia y Perú}

\begin{abstract}
Resumen
Este artículo trata de las vicisitudes de los pueblos conocidos hoy como Manchineri y Jaminawa, habitantes de las regiones fronterizas del departamento de Pando en Bolivia, de Madre de Dios en el Perú y del estado de Acre en Brasil. Busca rastrear sus conexiones y la pertinencia de suyas identidades históricas como pueblos de filiación lingüística y cultural Arawak y Pano, apuntar como fueran involucrados por el proceso de la expansión de las sociedades nacionales de Bolivia, Perú y Brasil, impulsados por la explotación del caucho en la región y, finalmente, mostrar como sus actuales definicciones políticas y identitárias y sus condiciones de vida fueron moldeadas por estos procesos. Pero, aunque moldeadas por estes processos y por las normas de los Estados nacionales que modificaran sus territorios quando se asignaram las fronteras nacionales, imponiendo los hitos "legítimos" para la vida de sus habitantes, apuntamos también como estos pueblos indígenas intentan utilizar en sus intereses los parámetros legales y socioculturales que buscan su dominación.
\end{abstract}

Palabras-clave: Manchineri, Jaminawa, fronteras, identidad, estado-nación, etnia.

Data de recebimento do artigo: 20/12/2009

Data de aprovação do artigo: 5/5/2010 